\title{
An Examination of Relative Clauses in Argumentative Essays Written by EFL Learners
}

\author{
Hesamoddin Shahriari \\ Ferdowsi University of Mashhad \\ Correspondence concerning this article should be addressed to Hesamoddin Shahriari, Ferdowsi \\ University of Mashhad, Azadi Square, Mashhad, Razavi Khorasan, Iran, 9177948974. \\ E-mail:h.shahriari@um.ac.ir
}

Farzaneh Shadloo

Ferdowsi University of Mashhad

Correspondence concerning this article should be addressed to Farzaneh Shadloo, Ferdowsi University of Mashhad, Azadi Square, Mashhad, Razavi Khorasan, Iran, 9177948974.

E-mail: farzaneh.shadloo@yahoo.com

\author{
Ahmad Ansarifar \\ Ferdowsi University of Mashhad \\ Correspondence concerning this article should be addressed to Ahmad Ansarifar, Ferdowsi University of \\ Mashhad, Azadi Square, Mashhad, Razavi Khorasan, Iran, 9177948974. \\ E-mail: ahmad.ansarifar@gmail.com
}

\begin{abstract}
Syntactic complexity has received a great deal of attention in the literature on second language writing. Relative clauses, which function as a kind of noun phrase post-modifier, are among those structures that are believed to contribute to the complexity of academic prose. These grammatical structures can pose difficulties for EFL writers even at higher levels of proficiency, and it is therefore important to determine the frequency and accuracy with which relative clauses are used by L2 learners since understanding learners' strengths and weaknesses in using these structures can inform teachers on ways to improve the process of their instruction in the writing classroom. This paper reports on a corpus-based comparison of relative clauses in a number of argumentative essays written by native and non-native speakers of English. To this end, 30 argumentative essays were randomly selected from the Persian sub-corpus of the ICLE and the essays were analyzed with respect to the relative clauses found in them. The results were then compared to a comparable corpus of essays by native speakers. Different dimensions regarding the structure of relative clauses were investigated. The type of relative clause (restrictive/non-restrictive), the relativizer (adverbial/pronoun), the gap (subject/nonsubject), and head nouns (both animate and non-animate) in our two sets of data were manually identified and coded. The findings revealed that the non-native writers tended to use a greater number of relative clauses compared to their native-speaker counterparts.
\end{abstract}

Keywords: relative clauses, learner writing, argumentative essays, ICLE, LOCNESS

Understanding syntactic complexity in second/ foreign language writing can be a major step towards improving the overall quality of teaching this important register in the university setting. It has recently been proposed that complexity in academic writing arises not from clausal subordination, but rather from phrasal embedding (Biber, Gray, \&
Poonpon, 2011). Corpus studies have shown that clausal subordination, which is used as a measure in calculating a number of complexity indices (e.g., the T-unit), is in fact more characteristic of registers such as conversation than academic writing (Biber et al., 2011). Research into noun phrases can be based on one of two possible definitions of this structure. A "noun 
phrase can be used as a cover term for two major types of constructions: noun-headed phrases and pronounheaded phrases" 1 . According to Biber et al.2, nounheaded phrases consist of four main components as shown below:

"Determiner + (premodification) + head noun + (postmodification and complementation)" This study focused on one type of noun phrase postmodification, namely the relative clause.

Relative clauses, which are characterized as a kind of noun phrase postmodifier, are generally classified into different categories. Diessel and Tomasello (2000) defined a relative clause as a "subordinate clause that modifies a noun or noun phrase in an associated main clause" (p. 132).

To date, there has been little agreement on whether a relationship exists between the frequency of relative clauses in learner writing and the learners' respective writing ability. For instance, in a study by Taguchi, Crawford, and Wetzel (2013), the authors found that there are more instances of that and wh-relative clauses in non-native essays of 'lower quality' compared to those of 'higher quality'. In stark contrast to this particular finding, Ferris (1994) reported that some syntactic features, among them relative clauses, were more frequent in papers written by more proficient ESL students. Similarly, Parkinson and Musgrave (2014) compared the frequency of noun phrase features in the writing of two groups of international students representing two different levels of proficiency and found that students of higher proficiency in writing tend to use more relative clauses compared to their lower-proficiency counterparts. While the previous research has mostly analyzed the use and role of relative clauses by spotting the differences between academic writing and conversation or among different academic writing sub-registers, fewer studies have compared English native and non-native speakers' writing in terms of using relative clauses.

Through this study, we hope to provide readers with a better understanding of the types of relative clauses that are frequently used by language learners and whether these patterns of use are similar to those used by writers who speak English as their first language. Previous studies have broadly looked at phrasal complexity in learner writing (e.g. Ansarifar, Shahriari, \& Pishghadam, 2018; Kreyer \& Schaub, 2018; Martínez, 2018; Parkinson \& Musgrave, 2014; Staples, Egbert, Biber, \& Gray, 2016; Yang, Lu, \& Weigle, 2015), but few have narrowed down their focus to a particular feature, such as relative clauses. As mentioned by Vyatkina, Hirschmann, \& Golcher

\footnotetext{
1 Biber, D., Johansson, S., Leech, G., Conrad, S., \& Finegan, E. (1999). Longman grammar of spoken and written English. Harlow, UK: Longman. P. 574

2 Ibid.
}

(2015), "not only ubiquitous global measures of syntactic complexity but also more specific measures, namely frequencies of syntactic modifiers, can serve as developmental indices at beginning L2 proficiency levels" (p. 28). A more focused analysis of features contributing to phrasal complexity in learner writing can greatly enhance our understanding of syntactic complexity as a whole. Therefore, in the present study, instead of examining complex noun phrases in general, we seek to analyze relative clause constructions in particular. Our study will also shed light on common errors in the use of relative clauses by learners in their argumentative essays.

The present study is guided by the following research questions:

1. How frequently do Iranian EFL writers make use of relative clauses in their argumentative essays?

2. How frequently do Iranian EFL writers make use of pied-piping relative clause structures in their argumentative essays?

3. How frequently do Iranian EFL writers make use of restrictive and non-restrictive relative clause constructions in their argumentative essays?

4. What kinds of head nouns (animate vs. nonanimate) are frequently modified by relative clauses found in argumentative essays by Iranian EFL writers?

5. What kinds of gaps can be observed in relative clause constructions found in argumentative essays by Iranian EFL writers?

6. Is there a significant difference between the frequency of relative clauses found in argumentative essays written by Iranian EFL writers and those written by L1 English writers?

While the first five questions are aimed at providing a descriptive account of the frequency with which various types of relative clauses are used by nonnative learners and native speakers of English, the final research question is central to the present study. The descriptive data will allow readers to interpret the final research question with a greater depth of understanding. For the last research question, a null hypothesis is formulated stating there is no significant difference between the frequency of relative clauses found in the two groups of essays.

\section{Review of the Literature}

According to Biber et al.3, relative clauses that modify a noun phrase can be considered as a form of

3 Ibid. 
finite clausal postmodification, while nonfinite clausal postmodifiers include ed-clauses, ing-clauses, and to-clauses. As Biber (2006) noted, there is also a kind of relative clause that is called the reduced relative clause. Quirk, Greenbaum, Leech, and Svartvik (1985) proposed a different classification of relative clauses. They suggested that there are three kinds of relative clauses, which they named adnominal relative clauses, nominal relative clauses, and sentential relative clauses. "Nominal relative clauses are unique...in that they 'contain' their antecedents" 4 . In sentential relative clauses, a clause is the antecedent of the relative clause5. Finally, the adnominal relative clause, which is the focus of this study, is the one that is used to modify a noun phrase6.

In terms of function, relative clauses fall into two major categories: restrictive and nonrestrictive. A restrictive relative clause adds information that is of significance for identifying the head noun; a nonrestrictive relative clause, on the other hand, adds extra information to further elaborate upon the head noun; and in the latter case, a comma is used to separate the head noun from the nonrestrictive relative clause ${ }^{7}$. Similarly, Parideaux and Baker (1987) mentioned that "non-restrictive relative clauses are more along the lines of parenthetical" (p. 50). Fabb (1990) also noted that due to the fact that a restrictive relative clause is a "predicate, it must modify a nominal, and so cannot take a wide range of categories as antecedents (as NRRs can)" (p. 76).

Regarding the frequency of relative clauses, it is explained that "overall, restrictive relative clauses are much more common than non-restrictive clauses (marked by a comma) in all written registers"s. The following are two examples of (a) a restrictive and (b) a nonrestrictive relative clause taken from Biber et al.'s ${ }^{9}$ :

(a) The capital outlay may not be justified by the area which may be expected to benefit by the improvement. (ACAD)

(b) He looked into her mailbox, which she never locked. (FICT)

Three main components of relative clauses are the head noun or antecedent, the gap, and the relativizer ${ }^{10}$. The head noun can either be animate or non-animate. Apparently, no research has been undertaken to examine the nature of head nouns in relative clauses and the frequency of each type of head noun in the

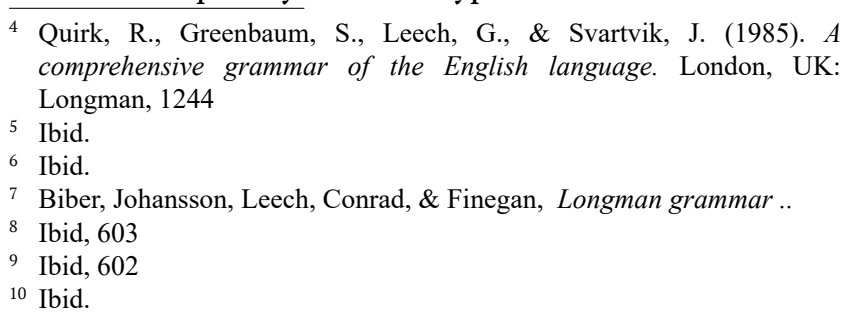

various sub-registers of academic writing. Relative clauses can either have a subject or a non-subject gap. Compared to subject gaps, which are more difficult, non-subject relative clauses are found to be more frequent in written registers ${ }^{11}$. Relativizers, which are another component of relative clauses, comprise two categories: (a) relative pronouns and (b) relative adverbs $^{12}$; and each include the following subcategories: "a relative pronoun--which, who, whom, whose, and that--or a relative adverb--where, when, and why. The relative pronoun can sometimes be omitted altogether (the zero relativizer)" ${ }^{\prime 3}$. Concerning the distribution of relativizers, Biber et al. ${ }^{14}$ found that the relativizers which and that are more commonly used in written registers.

English Relative clauses have been examined in different studies to compare different registers and/ or languages (e.g., native vs. non-native speaker) and even to make comparisons within a sub-register of one language; and different studies have presented different pictures of the function and use of relative clauses. For instance, a study of spectroscopic articles in Physical Review showed that the percentage of relative clauses decreased from $54 \%$ of subordinate clauses in $1893-95$ to $17 \%$ in 1980 and the author mentioned that this grammatical structure does not add to the 'intellectual complexity' (Bazerman, 1984). But in 1998, Kopple's study, which was a replication of Bazerman's study (1984) with some changes in the methodology and selection of the papers, indicated a slight drop (less than three percentage points) in the frequency of relative clauses from the earliest articles to the later articles, but dramatic differences in what they modified were observed (Kopple, 1998). Regarding the frequency of relative clauses, similarly, Biber and Clark (2002) noted that relative clauses are the most common type of clausal postmodifiers in written discourse, but as for their frequency through time, subtle changes were detected over the past 100 years.

Many studies have analyzed the use of relative clauses in academic writing for the purposes of drawing comparisons with spoken English or among the sub-registers of written discourse. For example, Biber and Gray (2010) indicated that more cases of relative clauses are observed in academic writing than in conversation, although this difference in frequency is not so great compared to prepositional phrases as noun postmodifiers, which are much more frequent in academic writing than conversation. In another study, it was noted that "finite relative clauses are much more common in writing than in conversation, but they are most common in newspaper writing and
11 Ibid.
12 Ibid.
13 Ibid, 608
14 Ibid. 
fiction rather than academic prose" (Biber, 2006, p. 14). Allen (2009) analyzed the role of relative clauses in a corpus of simplified news texts from three different levels, namely elementary, intermediate, and advanced. The results of his study showed that "although many RCs are retained in unmodified form across the levels, RCs are also found to be unique to specific levels, highlighting their role as simplifying devices used to modify lower level texts" (Allen, 2009 , p. 585). Although traditionally many studies have considered clausal subordination measures and length of T-unit as features related to grammatical complexity in L2 writing, recently, especially after the Biber et al.' (2011) study, the focus has shifted to the noun phrasal features for predicting complexity in writing development in which relative clauses are part of the hypothesized stages proposed in this respect.

While there has been some effort to further our understanding of the use of relative clauses in learner writing, there is still much work to be done in this domain and the results from previous studies on the relationship between the use of relative clauses and the level of learners' proficiency are also somewhat inconsistent, indicating the need for a more thorough examination of the use of relative clauses in different genres of learner writing.

One important and widely-investigated register of writing is the argumentative essay. Regarding the importance of the argumentative essay, Parkinson and Musgrave (2014) point out that such essays "introduce students to the rhetorical device of presenting an argument which is very common across a range of academic disciplines and which students may be expected to use in a wide range of assignment genres" (p. 52). Nippold, Ward-Lonergan, and Fanning (2005) also note that this type of writing is a "demanding task that requires the use of complex language to analyze, discuss, and resolve controversies in a way that is clear, convincing, and considerate of diverse points of view" (Nippold et al., 2005, p. 125). Finally, Crowhurst (1990) mentions that argumentative writing is significant "both for academic success and for general life purposes” (p. 349).

Many university programs now require students to practice their academic writing skills by composing argumentative texts, and the "educational challenge that many university EFL students face is the production of written academic arguments as part of their required essays" (Bacha, 2010, p. 229). As a result, numerous studies have been carried out to provide a better understanding of the lexico-grammatical features of learner writing in argumentative essays. Since the elements of persuasion and critical evaluation are of crucial importance in argumentative essays (i.e., the writer has to support his/her position regarding a particular issue) and because relative clauses have been said to perform an evaluative and persuasive function in writing (Tse \& Hyland, 2009), an investigation of these structures in argumentative essays by second/foreign language learners can be of particular interest and significance. In spite of this, relatively little attention has been paid to the role of relative clauses in this particular register.

\section{Materials and Methods}

\section{Data collection}

The corpus used in this study consisted of 60 learner-written argumentative essays (199,215-word tokens). One sub-corpus of this study consisted of 30 essays written by students majoring in English as a foreign language both at the undergraduate and graduate levels at Ferdowsi University of Mashhad. In this regard, students were asked to write their essays in at least 700 words on a predefined topic and under untimed conditions. In addition to writing the essay, participants were also asked to complete a learner profile form (see Appendix) in which they were required to answer some questions about their language learning background, such as the languages they knew, the number of years they had studied English and whether or not they had formerly resided in an English-speaking country. They were also asked to mention the resources they had used in composing the essay. The topic of the 30 essays included in the learner corpus was: The prison system is outdated. No civilized society should punish its criminals; it should rehabilitate them. Finally, by signing the learner profile form, they consented to having their essay used for research purposes. A parallel corpus of argumentative essays by native speakers of English was also used. This corpus also consisted of the same number of essays randomly selected from the Louvain Corpus of Native-speaker Essays (LOCNESS) with approximately the same number of words. Argumentative essays in the LOCNESS were written by undergraduate students for whom English was a native language. The topics of the 30 essays from LOCNESS dealt with issues related to capital punishment, crime, and feminism. LOCNESS includes also includes literary essays, which were not included in the present study. Table 1 shows the details of the two corpora used in the present study.

Table 1

\begin{tabular}{cccc}
\multicolumn{5}{c}{ The NS and NNS Corpus of the Study } \\
\hline Corpus & $\begin{array}{c}\text { Number of } \\
\text { essays }\end{array}$ & $\begin{array}{c}\text { Average essay } \\
\text { length }\end{array}$ & $\begin{array}{c}\text { Total number of } \\
\text { words }\end{array}$ \\
NS & 30 & 585.40 & 17,562 \\
NNS & 30 & 656.10 & 19,027 \\
\hline
\end{tabular}




\section{Coding}

As mentioned in the Review of the Literature, relative clauses can be either restrictive or nonrestrictive15, and in our analysis, whenever a relative clause served to add extra information to the head noun, it was identified as a non-restrictive relative clause. The reduced relative clauses and sentence relatives were not featured in the present study; and pied-piping relative clauses were separately categorized due to their different structure and analyzed in our two sets of writing. Relativizers are divided into two categories based on Biber et al.'s16 classification: relative pronouns (which, who, whom, whose, and that) and relative adverbs (where, when, and why). Zero-relativizers were not included in our analysis. As for head nouns, we used Biber's (2006) semantic classification of nouns which incorporates eight categories: animate, cognitive, concrete, technical/ concrete, place, quantity, group/institution, and abstract/ process; but the difference was that in this study, just two categories for the head nouns were considered, which were animate head nouns (humans or animals) versus non-animate head nouns.

\section{Procedure}

First, all relative clauses and pied-piping relative clauses were manually highlighted and checked in the two sets of essays. Then, the frequency of restrictive and non-restrictive relative clauses was separately calculated manually. Among the identified relative clauses, the frequency of instances with relative pronouns and those with relative adverbs were compared. As suggested by Biber (1988), that relative clauses were checked in order to exclude instances of that complements and any instances of that which functioned as a demonstrative pronoun. To identify the type of head noun (animate vs. non-animate) that is more frequently modified in relative clauses within learners' writing, their frequency was calculated. Finally, the occurrence of each subject gap in all the identified relative clauses was manually coded to differentiate between subject and non-subject gaps in our two sets of essays.

\section{Results and Discussion}

The total number of relative clauses (both restrictive and non-restrictive) in 30 argumentative essays written by Iranian EFL writers was 232 (about 12 cases per 1,000 words and about three cases in ${ }^{15}$ Ibid. every essay). A similar frequency count was carried out for the corpus of essays written by native English speakers, through which 137 relative clauses were identified (approximately seven cases per 1,000 words and about two cases in every essay; see Table 1). Overall, the frequency of relative clauses was higher in essays written by Iranian EFL writers than in native speaker essays.

Table 2 presents the overall frequency of relative clauses in argumentative essays written by Iranian writers and native English-speaking writers.

Table 2

Number of Relative Clauses per 1000 Words

\begin{tabular}{lcc}
\hline Feature & NNS & NS \\
Relative clause & 12 & 7 \\
\hline
\end{tabular}

The results shown in Table 2 may be explained by the fact that more explicit instructions regarding the use of relative clauses might have been offered to Iranian learners compared to native speakers of English. This would lead to the greater use of these structures for the modification of nouns compared to other forms of noun modifiers (i.e., appositives, participle- and prepositional post-modifiers) that are commonly observed in English written discourse17.

Regarding the frequency of pied-piping relative clauses, which were separately analyzed in our study, frequency counts suggest that pied-piping structures were rarely used by both native speakers (about one case per 1,000 words) and Iranian students (0.6 instances per 1,000 words). Table 3 represents the frequency of pied-piping relative clauses.

Table 3

Number of Pied-piping Relative Clauses per 1000 Words

\begin{tabular}{lcc}
\hline Feature & NNS & NS \\
Relative clause & 0.6 & 1 \\
\hline
\end{tabular}

According to Richards and Schmidt ${ }^{18}$, pied-pining structures "are felt by many speakers of English nowadays to be quite unnatural and in some cases unacceptable" (p. 414). Therefore, the rare use of piedpining relative clauses is not unexpected.

Excerpts from essays of both non-native and native speakers of English:

$$
\begin{aligned}
& \text {...the idea of "group therapy" in which a } \\
& \text { number if criminals gather together... }
\end{aligned}
$$

...the ways in which knowledge is conveyed....

The third research question of this study pertains to the frequency of restrictive and non-restrictive ${ }_{17}$ Ibid. 
relative clauses (see Table 4).

Table 4

Proportions of Restrictive and Non-restrictive Relative Clauses

\begin{tabular}{lcc}
\hline Feature & $\begin{array}{c}\text { NNS (232 rel. } \\
\text { clauses) }\end{array}$ & $\begin{array}{c}\text { NS (137 rel. } \\
\text { clauses) }\end{array}$ \\
Restrictive relative clause & $88.79 \%$ & $91.97 \%$ \\
Non-restrictive relative clause & $11.20 \%$ & $8.02 \%$
\end{tabular}

As can be seen in Table 4, the percentage of relative clauses that are restrictive in Iranian argumentative essays is approximately $88.79 \%$; while it constitutes about $91.97 \%$ of relative clauses in essays by native English-speaking writers. This finding suggests that in argumentative essays written by both groups, restrictive relative clauses are used more frequently than non-restrictive relative clauses. However, a comparison between the two corpora reveals that native English speakers have used a slightly greater percentage of restrictive relative clauses in their essays. These results are in line with Biber et al.'s ${ }^{19}$ finding that "restrictive relative clauses are much more common than non-restrictive clauses (marked by a comma) in all written registers" (p. 603). However, approximately $15 \%$ of relative clauses are non-restrictive in academic prose and fiction ${ }^{20}$. On the other hand, in essays written by Iranian EFL writers, only about $11.20 \%$ of relative clauses are non-restrictive and this type of relative clause forms about $8.02 \%$ of relative clauses in native speakers' essays.

Excerpts from essays of both non-native and native speakers of English:

\section{A person who does not like a certain minority avoids being around that minority... (Restrictive relative clause)}

\section{Another novel that shows transmission of cultures is Walker's The Color Purple. (Non-restrictive relative clause)}

Out of 232 relative clauses in Iranian essays, 12 cases (about 5.17\%) included relative adverbs; and out of 137 relative clauses in native speaker essays, nine cases (about 6.56\%) of relative adverbs were observed (see Table 5).

Table 5

Number and Percentage of Relativizers Across Argumentative Essays Written by Iranian EFL Writers and Native English-Speaking Writers

${ }_{20}$ Ibid.

\begin{tabular}{ccc}
\hline \multicolumn{1}{c}{ Feature } & $\begin{array}{c}\text { NNS (232 rel. } \\
\text { clauses) }\end{array}$ & $\begin{array}{c}\text { NS (137 rel. } \\
\text { clauses) }\end{array}$ \\
Relative pronoun & $220(94.82 \%)$ & $128(93.43 \%)$ \\
Relative adverb & $12(5.17 \%)$ & $9(6.56 \%)$ \\
\hline
\end{tabular}

As can be seen in Table 5, both groups of writers were found to use relative pronouns more frequently as compared to relative adverbs. This observation is consistent with the results shown in Figure 8.17 in Biber et al.'s ${ }^{21}$ study, which indicates that in academic prose, relative adverbs such as where, when, and why are not as frequent as relative pronouns (i.e., who, which, that).in academic prose.

Among relativizers, the results indicated that Iranian writers used the that relativizer more frequently (90 cases out of 232 relativizers). In essays written by Iranian writers, after that, the relativizer who (70 cases out of 232 relativizers) was more frequent and the third most frequent relativizer was which (44 cases out of 232 relativizers). These results differ from Biber et al.'s ${ }^{22}$ findings which found that in academic prose, the which relativizer is the most frequentlyobserved relativizer; they also noted that that relativizers are very frequent as well, but not as much as which; and after these two relativizers, who is quite frequently observed in academic prose. Therefore, Iranian EFL writers seem to use the relativizer who more frequently, and they appear to use which less frequently than that. A possible explanation for this tendency towards using that might be that they have used more restrictive relative clauses in their essays, and as suggested by Biber et al. ${ }^{23}$, which is mostly used with non-restrictive relative clauses and "that rarely occurs with non-restrictive clauses" (p. 615). Another possible explanation for this is that both groups in our study used more non-animate head nouns. Again, it was noted by Biber et al. ${ }^{24}$ that which relativizers are rarely used with relative clauses containing animate head nouns. A further possible explanation for this is that the that relativizer is used more frequently in conversation and this may be due to the influence of conversation that led both groups of writers in our study to use it more frequently because according to Biber et al. ${ }^{25}$, "in conversation, which is relatively rare, while that is moderately common" (p. 611). It could thus be argued that the reason Iranian writers used who more than which is due to this fact that they used more animate head nouns in their argumentative essays.

The fourth research question required analyzing the type of head noun (animate vs. non-animate) that

\footnotetext{
21 Ibid.

22 Ibid.

23 Ibid.

24 Ibid.

25 Ibid.
} 
is more frequently modified in relative clauses used in argumentative essays written by both Iranian and native English-speaking writers (see Table 6).

Table 6

The Frequency and Percentage of Head Nouns Modified in Relative Clauses Across Argumentative Essays Written by Iranian EFL Writers and Native English-Speaking Writers

\begin{tabular}{lcc}
\hline \multicolumn{1}{c}{ Feature } & NNS & NS \\
Animated head noun & $5(43.10 \%)$ & $3(41.60 \%)$ \\
Non-animated head noun & $6(56.89 \%)$ & $4(58.39 \%)$ \\
\hline
\end{tabular}

Note. Frequency counts are normed to 1,000 words

The results, as shown in Table 6 , indicate that both groups in our study used more non-animate head nouns in their essays. The normalized frequency counts suggest that there were five $(43.10 \%)$ animate head nouns versus six $(56.89 \%)$ non-animate versus per 1,000 words in Iranian essays and three (41.60\%) animate head nouns versus four (58.39\%) non-animate per 1,000 words in essays written by native Englishspeaking writers. Furthermore, the proportion of animate head nouns to non-animate head nouns in both datasets was remarkably similar.

Excerpts from essays of both non-native and native speakers of English:

...the individuals who supply drugs in a country.... (Animate head nouns)

The first thing that someone might imagine... (Non-animate head nouns)

...people who speak a wide variety of languages.... (Animate head nouns)

...hardships that they went through... (Nonanimate head nouns)

Regarding the fifth research question, this study found that the majority of the relative clauses in both cohorts had subject gaps. Table 7 summarizes the frequency of subject versus non-subject gaps in relative clauses that were used in essays by Iranian and native English-speaking writers.

Table 7

Number and Percentage of Subject and Non-Subject Gaps in Relative Clauses Across Argumentative Essays Written by Both Groups

\begin{tabular}{lcc}
\hline \multicolumn{1}{c}{ Feature } & $\begin{array}{c}\text { NNS (232 rel. } \\
\text { clauses) }\end{array}$ & $\begin{array}{c}\text { NS (137 rel. } \\
\text { clauses) }\end{array}$ \\
Subject gaps & $188(81.03 \%)$ & $94(68.61 \%)$ \\
Non-subject gaps & $44(18.96 \%)$ & $43(31.38 \%)$ \\
\hline
\end{tabular}

As can be seen in Table 7, subject gaps in relative clauses are more commonly used than non-subject gaps among essays written by both Iranian writers (188 cases out of 232 relative clauses; about $81.03 \%$ ) and native English-speaking writers (94 cases out of 137 relative clauses; about $68.61 \%$ ). These results are consistent with the Longman Grammar of Spoken and Written English ${ }^{26}$, which reported that although subject gaps are reportedly processed more easily, they are more commonly used in writing than in conversation. Generally, native English-speaking students use more non-subject gaps than Iranian students and this result may be explained by the fact that non-subject gaps are more difficult to form, as claimed in Biber et al.' $\mathrm{s}^{27}$ study.

Excerpts from essays of both non-native and native speakers of English:

...someone who has killed one... (Subject gap)

... the first thing that someone might imagine...(Non-subject gap)

...children who did not realize what a gun could do... (Subject gap)

...reality that we experience... (Non-subject gap)

Table 8 shows the mean value for relative clauses per 1000 words. To determine whether the mean values of relative clauses for NS and NNS groups differ significantly from each other, an independent-sample t-test was run. The t-test results are also summarized in Table 8.

The results reveal statistically significant differences $(p<.005)$ in the mean values of total relative clauses and both restrictive and non-restrictive relative clauses.

As shown in Table 8, Iranian NNS used a significantly greater number of relative clauses (both restrictive and non-restrictive) compared to their NS counterparts. This is largely consistent with findings reported in previous studies. Biber et al. (2011), in their proposed developmental stages of syntactic complexity, predicted that finite dependent clauses (e.g., relative clauses) are acquired during the early stages of writing development, while non-finite dependent clauses (e.g., -ed and -ing clauses) are not observed until later stages of writing development. This particular difference in the use of relative clauses by the two groups of writers in our study supports Biber et al.'s (2011) proposed model of syntactic complexity. In other words, the Iranian writers relied more on an early-stage grammatical feature (i.e., relative clause) compared to NSs, whose writing proficiency lies 26 Ibid.

27 Ibid. 
at the more highly developed end of the spectrum. Staples et al. (2016) also argued that there are clear developmental trends in writing development: as proficiency levels increase, there is a reduction in the clausal features and a concurrent increase in phrasal features. What these studies suggest is that writing from lower levels tends to rely more heavily on clausal features (e.g., relative clauses) while the higher levels tend to include more phrasally complex features. The more frequent occurrence of relative clauses in the corpus of NNS essays supports this hypothesis.

Biber, Gray, and Poonpon (2013) argued that the greater use of relative clauses by ESL/EFL students is due to the instruction they receive on this structure. They noted that even advanced levels of ESL grammar books, such as Focus on Grammar 3, Grammar Sense 3, and Grammar Links 3, extensively cover finite dependent clauses (e.g., conditionals and relative clauses).

Our findings also support a recent study by Staples, Egbert, Biber, and Gray (2016) in which the development of phrasal and clausal features in the writing of university students across different academic levels was examined. The authors of the latter study concluded that there are "clear developmental trends in the academic writing of L1 university-level writers" (p. 30-31). The lower-level students in their study were found to mainly use clausal features (particularly finite clauses), while the higher-level students produced more phrasal features.

\section{Conclusion}

This study investigated the frequency of relative clauses in 30 argumentative essays randomly selected from the Iranian sub-corpus of the ICLE and the results were then compared with the same number of essays written by American university students (randomly selected from the LOCNESS argumentative corpus). Different dimensions of relative clauses such as restrictive vs. non-restrictive relative clauses, relativizers, subject vs. non-subject gaps, and head nouns were analyzed in this study. Our findings showed that upper-intermediate to advanced Iranian EFL writers in this sample generally tended to use more relative clauses in their essays compared to native English-speaking writers.

The findings of this study can be of great importance to L2 writing instructors and material developers since it sheds light on differences between writing by L2 learners and writing by NSs by drawing a comparison between the use of relative clauses in the two. These differences must be carefully taken into account when designing appropriate pedagogical materials to facilitate NNS learners' syntactic development.

Given the scope of this study, a number of issues should be mentioned so they can be considered in future studies. First, due to the small sample size of the two datasets used in this study, we could not provide a detailed explanation for less common kinds of relative clauses such as pied-piping. Such features can be examined in greater depth in future investigations. A further limitation of this study is that we compared our results, which are based on argumentative essays, with results obtained from academic writing in general. One reason for this is that very few resources based exclusively on argumentative essays are available for us to make more detailed comparisons in this respect.

In addition, since Biber et al. (2011) have argued that clausal structures are more characteristic of spoken rather than the written language, future investigations can analyze relative clauses in NNS spoken discourse and compare them to written registers. This would allow us to see whether the same differences are observable between spoken and written discourse by NNSs. Third, the present study examined essays by upper-intermediate to advanced-level writers; future studies can explore the use of relative clauses across different proficiency levels. Finally, this study attempted to examine relative clauses in essays by Iranian EFL students. Lu and Ai (2015) argued that the L1 background plays an important role in the development of syntactic complexity. Therefore, future studies can investigate the use of relative clauses in the writing of learners from other L1 backgrounds.

Table 8

Statistical Analysis of Relative Clauses in the NS and NNS Corpora

\begin{tabular}{|c|c|c|c|c|c|c|c|}
\hline \multirow{2}{*}{ Grammatical Structure } & \multicolumn{2}{|c|}{ NS } & \multicolumn{2}{|c|}{ NNS } & \multirow[b]{2}{*}{$\mathrm{t}$} & \multirow[b]{2}{*}{ df } & \multirow[b]{2}{*}{$\mathrm{p}$} \\
\hline & M & SD & M & SD & & & \\
\hline Relative clause & 7.705 & 3.495 & 12.388 & 4.861 & -4.284 & 58 & .000 \\
\hline Restrictive relative clause & 7.076 & 3.283 & 11.031 & 4.838 & -3.704 & 51.035 & .001 \\
\hline Non-restrictive relative clause & .628 & 1.066 & 1.356 & 1.566 & -2.105 & 51.133 & .040 \\
\hline
\end{tabular}




\section{References}

Ansarifar, A., Shahriari, H., \& Pishghadam, R. (2018). Phrasal complexity in academic writing: A comparison of abstracts written by graduate students and expert writers in applied linguistics. Journal of English for Academic Purposes, 31, 58-71.

Allen, D. (2009). A study of the role of relative clauses in the simplification of news texts for learners of English. System, 37(4), 585-599. doi: 10.1016/j. system.2009.09.004

Bacha, N. N. (2010). Teaching the academic argument in a university EFL environment. Journal of English for Academic Purposes, 9(3), 229-241. doi: 10.1016/j. jeap.2010.05.001

Bazerman, C. (1984). Modern evolution of the experimental report in physics: Spectroscopic articles in physical review, 1893-1980. Social Studies of Science, 14(2), 163-196. doi: 10.1177/030631284014002001

Biber, D. (1988). Variation across speech and writing. Cambridge, UK: Cambridge University Press.

Biber, D., Johansson, S., Leech, G., Conrad, S., \& Finegan, E. (1999). Longman grammar of spoken and written English. Harlow, UK: Longman.

Biber, D. (2006). University language: A corpus-based study of spoken and written registers. Amsterdam, the Netherlands: John Benjamins.

Biber, D., \& Clark, V. (2002). Historical shifts in modification patterns with complex noun phrase structures: How long can you go without a verb? In T. Fanego, M. J. López-Couso \& J. Pérez-Guerra (Eds.), English historical syntax and morphology: Selected papers from 11 ICEHL (pp. 43-66). Amsterdam, the Netherlands: John Benjamins.

Biber, D., \& Gray, B. (2010). Challenging stereotypes about academic writing: Complexity, elaboration, explicitness. Journal of English for Academic Purposes, 9(1), 2-20.doi: 10.1016/j.jeap.2010.01.001

Biber, D., Gray, B., \& Poonpon, K. (2011). Should we use characteristics of conversation to measure grammatical complexity in L2 writing development? TESOL Quarterly, 45(1), 5-35. doi:10.5054/ tq.2011.244483

Biber, D., Gray, B., \& Poonpon, K. (2013). Pay attention to the phrasal structures: Going beyond T-units - A response to Wei Wei Yang. TESOL Quarterly, 47(1), 192-201.

Crowhurst, M. (1990). Teaching and learning the writing of persuasive/argumentative discourse. Canadian Journal of Education / Revue Canadienne De L'éducation, 15(4), 348. doi: 10.2307/1495109

Diessel, H., \& Tomasello, M. (2000). The development of relative clauses in spontaneous child speech. Cognitive Linguistics, 11(1/2), 131-152. doi: 10.1515/ $\operatorname{cog} 1.2001 .006$

Fabb, N. (1990). The difference between English restrictive and nonrestrictive relative clauses 1. Journal of Linguistics, 26(1), 57-77. doi: 10.1017/ S0022226700014420

Ferris, D. (1994). Lexical and syntactic features of ESL writing by students at different levels of L2 proficiency. TESOL Quarterly, 28(2), 414-420.doi: $10.2307 / 3587446$

Hyland, K. (1990). A genre description of the argumentative essay. RELC Journal, 21(1), 66-78. doi: $10.1177 / 003368829002100105$

Kopple, W. (1998). Relative clauses in spectroscopic articles in the physical review, beginnings and 1980: Some changes in patterns of modification and a connection to a possible shift in style. Written Communication, 15(2), 170-202. doi:10.1177/0741088398015002002

Kreyer, R., \& Schaub, S. (2018). The development of phrasal complexity in German intermediate learners of English. International Journal of Learner Corpus Research, 4(1), 82-111.

$\mathrm{Lu}$, X., \& Ai, H. (2015). Syntactic complexity in college-level English writing: Differences among writers with diverse L1 backgrounds. Journal of Second Language Writing, 29, 16-27. doi:10.1016/j. jslw.2015.06.003

Martínez, A. C. L. (2018). Analysis of syntactic complexity in secondary education ELF writers at different proficiency levels. Assessing Writing, 35, 1-11.

Nippold, M. A., Ward-Lonergan, J. M., \& Fanning, J. L. (2005). Persuasive writing in children, adolescents, and adults. Language Speech and Hearing Services in Schools, 36(2), 125-138. doi:10.1044/01611461(2005/012)

Parkinson, J., \& Musgrave, J. (2014). Development of noun phrase complexity in the writing of English for academic purposes students. Journal of English for Academic Purpose, 14, 48-59. doi:10.1016/j. jeap.2013.12.001

Prideaux, G. D., \& Baker, W. J. (1987). Strategies and structures: The processing of relative clauses. Amsterdam, the Netherlands: John Benjamins Publishing.

Quirk, R., Greenbaum, S., Leech, G., \& Svartvik, J. (1985). A comprehensive grammar of the English language. London, UK: Longman.

Staples, S., Egbert, J., Biber, D., Gray, B. (2016). Academic writing development at the University level phrasal and clausal complexity across level of study, discipline, and genre. Written communication, 33(2), 149-183.

Taguchi, N., Crawford, W., \& Wetzel, D. Z. (2013). What linguistic features are indicative of writing quality? A case of argumentative essays in a 
college composition program. TESOL Quarterly, 47(2), 420-430. doi: 10.1002/tesq.91

Tse, P., \& Hyland, K. (2010). Claiming a territory: Relative clauses in journal descriptions. Journal of Pragmatics, 42(7), 1880-1889. doi:10.1016/j. pragma.2009.12.02

Vyatkina, N., Hirschmann, H., \& Golcher, F. (2015). Syntactic modification at early stages of L2 German writing development: A longitudinal learner corpus study. Journal of Second Language Writing, 29, 28-50. Yang, W., Lu, X., \& Weigle, S. C. (2015). Different topics, different discourse: Relationships among writing topic, measures of syntactic complexity, and judgments of writing quality. Journal of Second Language Writing, 28, 53-67. 


\section{Appendix}

LEARNER PROFILE

Text code: (do not fill in)

Essay:

Title:

Approximate length required: $\quad-500$ words $0 \quad+500$ words

0

Conditions: timed 0 untimed

0

Examination: yes 0

$\begin{array}{llll}\text { No } & 0 & & \\ \text { Reference tools: } & \text { yes } 0 & \text { no }\end{array}$

0

What reference tools?

Bilingual dictionary:-

English monolingual dictionary:

Grammar:-

Other(s):-

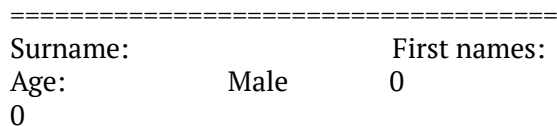

0

Nationality:

Native language:

Father's mother tongue:

Mother's mother tongue:

Language(s) spoken at home: (if more than one, please give the average \% use of each)

Education:

Primary school - medium of instruction:

Secondary school - medium of instruction:

Current studies:

Current year of study:

Institution:

Medium of instruction:

English only 0

Other language(s) (specify) 0

Both 0

Years of English at school:

Years of English at university:

Stay in an English-speaking country:

Where?

When? How long?

Other foreign languages in decreasing order of proficiency:

I hereby give permission for my essay to be used for research purposes.

Date: Signature: 